\title{
La institucionalidad estatal de derechos humanos y la creación del Instituto de Derechos Humanos en Chile
}

Este comentario, junto a los documentos que analiza, está disponible en www.anuariocdh.uchile.cl

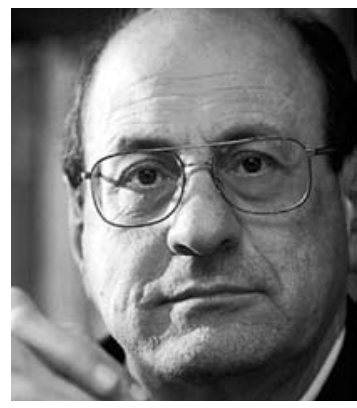

\section{José Zalaquett}

Abogado, Licenciado en Ciencias Jurídicas y Sociales por la Universidad de Chile, Doctor en Derecho, Honoris Causa, por las universidades de Notre Dame y City University of New York. Es profesor de Derechos Humanos de la Facultad de Derecho de la Universidad de Chile. Participó en la Comisión de Verdad y Reconciliación y la Mesa de Diálogo. Fue elegido como miembro de la Comisión Interamericana de Derechos Humanos entre los años 2000 y 2005, siendo Presidente en el período 2003 y 2004.

jzalaque@derecho.uchile.cl

\section{RESUMEN}

El artículo revisa cómo se inserta el nuevo Instituto de Derechos Humanos en el desarrollo de la institucionalización de la promoción y protección de los derechos humanos, contrastando su diseño legal con los Principios de París Relativos al Estatuto y Funcionamiento de las Instituciones Nacionales de Protección y Promoción de los Derechos Humanos.

El día 12 de diciembre de 2009 se publicó en el "Diario Oficial" de la República de Chile la Ley N²0.405, Ilamada "Del Instituto Nacional de Derechos Humanos". La creación de este organismo (en adelante "el Instituto") fue calificada, en declaraciones de gobierno, como un avance mayor en el proceso de fortalecimiento de la institucionalidad del Estado de Chile en materia de promoción y protección de los derechos humanos ${ }^{1}$. Por su parte, organizaciones de familiares de víctimas de violaciones de derechos humanos y algunos personeros políticos dieron a conocer opiniones críticas sobre la Ley $\mathrm{N}^{\circ} 20.405^{2}$.

Con la promulgación de este cuerpo legal se cumplía una nueva etapa en un complejo proceso legislativo iniciado el 12 de agosto de 2003, cuando el entonces Presidente de la República, Ricardo Lagos, divulgó un documento sobre nuevas políticas estatales en materia de derechos humanos, denominado "No Hay Mañana Sin Ayer". En éste, el Presidente Lagos anunciaba, entre otras medidas, la creación de un "Instituto Nacional de Derechos Humanos y Libertades Públicas"3.

La creación de dicho Instituto se impulsó mediante diversos textos de proyectos de ley, los que fueron objeto de muchas consultas, enmiendas y negociaciones parlamentarias. Estas se extendieron

\footnotetext{
Ver, entre otras referencias, el sitio web, http://www.sernac.cl/acercade/Resumen\%20Program\%C3\%A1tico\%2020062010.pdf, consultado el 5 de abril de 2010.

2 Ver, entre otras referencias, el sitio web, http://www.unexpp.cl/home/?p=1299, consultado el 5 de abril de 2010.

3 Ver www.lanacion.cl/p4.../20030812212921.html?0, consultado el 5 de abril de 2010.
} 
virtualmente durante todo el mandato de la Presidenta Michelle Bachelet (11 de marzo de 2006 al 11 de marzo de 2010). Dada la composición política del Parlamento en la época de la tramitación de esta iniciativa, el resultado final de dicho proceso fue una conciliación de los puntos de vista del gobierno y la oposición. La fecha de establecimiento efectivo del Instituto es, al momento de concluirse este artículo, incierta ${ }^{4}$.

Por tanto, el análisis del presente artículo tomará en cuenta sólo el texto de la Ley № 20.405 . Tal examen se realizará a la luz de los llamados Principios de París, que inspiraron mucho de su contenido. Previamente, se expondrán algunas consideraciones de contexto sobre el tipo de organización estatal que se intenta crear mediante dicha ley y sobre los alcances de la iniciativa de crear el Instituto, dentro del cuadro de los avances que se han Ilevado a cabo en Chile en materia de institucionalidad de protección y promoción los derechos humanos.

\section{Institucionalización de la promoción y protección de los derechos humanos en Chile}

A partir de la transición política que tuvo lugar en Argentina, comenzando en 1983, y de muchos otros procesos de cambio político que se sucedieron, posteriormente, en distintas latitudes, todos ellos marcados por los intentos de superar un pasado reciente de dictadura y/o guerra civil que dejó un legado de sistemáticas violaciones de derechos humanos y crímenes de guerra, se ha desarrollado, internacionalmente, un campo de teoría y práctica que ha llegado a ser conocido como Justicia Transicional ${ }^{5}$.

Uno de los postulados de la teoría de la Justicia Transicional es que parte importante del proceso de reconstrucción política y moral de un país, luego de un período de graves violaciones de los derechos fundamentales, consiste en el fortalecimiento institucional del respectivo sistema jurídico-político, en lo que toca a las garantías democráticas y de vigencia del estado de derecho, con énfasis en la protección y promoción de los derechos humanos ${ }^{6}$.

Con este propósito, en las últimas tres décadas se han establecido, en distintos países, nuevas instituciones. Se trata de órganos estatales autónomos ${ }^{7}$ que, como tales, forman parte de una creciente tendencia internacional hacia la creación de este tipo de entidades en las democracias

4 Luego de la asunción del mando del Presidente Sebastián Piñera, el 11 de marzo de 2010, tuvo lugar, el día 27 de ese mes, una sesión de la Comisión de Derechos Humanos de la Cámara de Diputados, a la que asistió el Ministro Secretario General de Gobierno. Éste informó que la tardanza en el funcionamiento del Instituto se debía, entre otros problemas, a un error en la asignación presupuestaria, el cual debía ser subsanado. Ver http://www.todoschile.cl/content/ view/749360/Ministro-Laurroulet-explica-la-demora-por-instalacion-del-instituto-Nacional-de-Derechos-Humanos. html, consultado el 20 de abril de 2010. Con posterioridad, el aparente problema presupuestario fue resuelto pero al momento de concluirse este comentario, subsistía una duda sobre si todos los nombramientos del Consejo del Instituto serían aceptados (mediante el acto Ilamado "toma de razón") por la Contraloría General de la República.

5 Dicha expresión, que a juicio de este autor no es feliz, fue utilizada originalmente en la publicación en tres volúmenes "Transitional Justice", editada por KRITZ, Neil. United States Institute of Peace, Washington, D.C., 1995. Contribuyó, luego, a la difusión de esta expresión, el establecimiento, en 2001, de la organización internacional especializada, con sede en Nueva York, que tomó el nombre de International Center for Transitional Justice.

6 Otros de los aspectos centrales del proceso de reconstrucción política y moral de un país que destaca la teoría de Justicia Transicional son: la investigación y revelación de la verdad sobre las más serias violaciones a los derechos humanos y los crímenes de guerra perpetrados en el pasado reciente; el reconocimiento social e institucional de tal verdad; reparaciones; y el sometimiento a proceso penal de los crímenes contra el derecho internacional.

7 Sobre organismos autónomos, ver: ACKERMAN, John M. Organismos autónomos y democracia: el caso de México. Siglo XXI, UNAM, Instituto de Investigaciones Jurídicas, México, 2007, pp. 17-44. También, VÁSQUEZ IRIZARRY, William. "Hacer cumplir las leyes" en la era de los órganos autónomos: reforma o abandono de la teoría del Poder Ejecutivo. Seminario en Latinoamérica de Teoría Constitucional y Política (SELA), marzo 2006, 27 pp. 
modernas ${ }^{8}$; sin embargo, dentro del género de entes estatales autónomos, estos nuevos organismos se caracterizan específicamente por su objetivo de proteger y/o promover derechos específicos, o bien un amplio rango de derechos humanos ${ }^{9}$. Además de la creación de entes autónomos, la tarea de reforzar la institucionalidad de protección y promoción de derechos humanos ha comprendido, entre otras medidas, el establecimiento de comisiones y otros organismos de tipo transitorio; la ratificación, por parte de los Estados, de tratados de derechos humanos, y la promulgación de nueva legislación nacional o bien la reforma de normas constitucionales y legales existentes.

Desde que retornó al sistema de gobierno democrático, el 11 de marzo de 1990, Chile ha adoptado diversas medidas de fortalecimiento de la institucionalidad de derechos humanos que se ajustan a los objetivos antedichos. Estas incluyen iniciativas para enfrentar el legado de violaciones de derechos humanos del pasado reciente ${ }^{10}$; reformas constitucionales ${ }^{11}$; nueva legislación o modificación de la legislación existente con anterioridad al retorno a la democracia, en materias tales como procedimiento penal, libertades civiles, justicia de familia, justicia laboral y derechos de la mujer ${ }^{12}$; ratificación de tratados y convenciones internacionales sobre derechos humanos ${ }^{13}$;

8 Entre los órganos autónomos que con mayor frecuencia se encuentran en la institucionalidad estatal de regímenes democráticos modernos, se pueden mencionar los siguientes: entes contralores de cuentas públicas y/o de la legalidad de los actos del Poder Ejecutivo; tribunales de control constitucional; bancos centrales (dotados de autonomía por la respectiva Constitución o por la ley); instituciones encargadas de la organización de elecciones populares y de velar porque se cumplan las reglas sobre campañas políticas y sobre sufragio.

9 Entre los órganos autónomos que se ocupan de un amplio rango de derechos humanos y que han sido adoptados por diversos países, se cuentan las oficinas de Ombudsman, que en distintos países de América Latina se conocen, por lo común, con nombres tales como Defensoría del Pueblo o Procuraduría de Derechos Humanos.

10 Entre ellas: la creación de la Comisión Nacional de Verdad y Reconciliación (1990-1991) y de su sucesora, la Corporación de Reparación y Reconciliación (1992-1995); el establecimiento de la Mesa de Diálogo sobre Derechos Humanos (19902000); la organización de un programa de Derechos Humanos del Ministerio del Interior (ver el sitio web http://www. ddhh.gov.cl/); y la creación de una Comisión Asesora Presidencial para la Protección de los Derechos de las Personas (ver sitio web http://www.comisiondefensoraciudadana.cl/) como substituto temporal y parcial de un órgano estatal de Defensoría del Ciudadano (o Defensoría del Pueblo), cuyo establecimiento ha sido impulsado virtualmente por dos décadas por organizaciones ciudadanas, pero respecto del cual no ha existido acuerdo político. Para un recuento de las medidas adoptadas en Chile hasta el año 2003, ver "No Hay Mañana Sin Ayer", documento publicado el 8 de agosto de 2003 por el Presidente Ricardo Lagos, en el sitio web http://www.archivochile.com/Derechos_humanos/doc_gen_ddhh/ prop/hhddprop0001.pdf, consultado el 5 de abril de 2010.

11 Entre las reformas constitucionales más relevantes, en materia de derechos humanos y temas afines, se encuentran; (i) las del año 1989 que modifican el artículo 5 de la Constitución para establecer que el ejercicio de la soberanía reconoce como limitación el respeto a los derechos esenciales que emanan de la naturaleza humana, y la que deroga el artículo 8 original de la Constitución de 1980, el cual declaraba la ilegalidad de determinadas doctrinas políticas; (ii) las reformas del año 2005 que eliminan diversos resabios autoritarios de la Constitución de 1980 e introducen un nuevo artículo 8 en el que se consagra el principio de transparencia de los actos y resoluciones del Estado.

12 Para consultar la legislación chilena pertinente, por temas y por fechas, ver el sitio web de la Biblioteca del Congreso Nacional de Chile: http://www.bcn.cl

13 Los tratados internacionales de derechos humanos y temas afines ratificados por Chile desde el retorno al país a la democracia, el 11 de marzo de 1990 (así como los retiros de reservas formuladas a otros tratados), son los que se indican a continuación, seguidos, en cada caso, del año de ratificación o retiro de reserva: Convención sobre los Derechos del Niño, 1990; Convención Americana sobre Derechos Humanos, 1991; retiro de reservas formuladas a la Convención Contra la Tortura y Otros Tratos o Penas Crueles, Inhumanos o Degradantes, adoptada por la Asamblea General de la Organización de las Naciones Unidas, 1991; retiro de reservas formuladas a la Convención Interamericana para Prevenir y Sancionar la Tortura, 1991; Protocolo Facultativo del Pacto Internacional de Derechos Civiles y Políticos, 1992; Convención sobre la Esclavitud, su protocolo y la convención suplementaria sobre la Abolición de la Esclavitud, Trata de Esclavos e Instituciones y Prácticas Similares a la Esclavitud, 1995; Convención Interamericana para Prevenir, Sancionar y Erradicar la Violencia Contra la Mujer, 1998; retiro de la reserva formulada al artículo 30, párrafo 1, de la Convención Contra la Tortura y Otros Tratos o Penas Crueles, Inhumanos o Degradantes, 1999; Convención Interamericana contra la Corrupción, 1999; Convención Interamericana para la Eliminación de Todas las Formas de Discriminación contra las Personas con Discapacidad, 2002; Protocolos Facultativos de la Convención sobre los Derechos del Niño, 2003; Convención Internacional sobre la Protección de los Derechos de Todos los Trabajadores Migratorios y de sus Familiares, 2005; Convención Interamericana contra el terrorismo, 2005; Convención de las Naciones Unidas contra la Corrupción, 2007; Protocolo a la Convención Americana sobre Derechos Humanos Relativo a la Abolición de la 
promulgación de una ley de acceso a información pública y la creación de un Consejo para la Transparencia encargado de aplicar esta legislación ${ }^{14}$.

\section{Los Principios de París}

En marzo de 1992, la entonces Comisión de Derechos Humanos de las Naciones Unidas (reemplazada por el Consejo de Derechos Humanos, en 2006) aprobó los Principios de París Relativos al Estatuto y Funcionamiento de las Instituciones Nacionales de Protección y Promoción de los Derechos Humanos ${ }^{15}$ (en adelante, PP). Estos principios habían sido elaborados en el año anterior, en una reunión en la que participaron funcionarios de Naciones Unidas y representantes de organizaciones gubernamentales y no gubernamentales, además de expertos independientes.

Los PP recomiendan que las instituciones nacionales de derechos humanos dispongan del mandato más amplio posible en el ámbito de la promoción y protección de los derechos humanos. Estas debieran incluir, entre muchas otras facultades, las atribuciones de (i) formular proposiciones de todo tipo (legislativas, administrativas, de organización o de políticas públicas, o bien relativas a casos que decida examinar) a las autoridades estatales; (ii) hacerlas públicas, si así lo estima; (iii) elaborar informes sobre la situación nacional de derechos humanos o sobre cuestiones específicas; (iv) cooperar con organismos internacionales de derechos humanos, y (v) contribuir a la enseñanza e investigación sobre estas materias.

Los PP también contienen criterios dirigidos a garantizar el pluralismo en la composición de las instituciones nacionales y los recursos necesarios para un funcionamiento suficiente y autónomo. En otra sección se establecen modalidades de funcionamiento de las mencionadas instituciones; éstas incluyen realizar investigaciones y estudios en la esfera de su competencia, recibir testimonios, informaciones y documentos; hacer públicas sus opiniones y recomendaciones; coordinarse con órganos estatales competentes en materias de su mandato y establecer relaciones con organizaciones no gubernamentales. Por último, los PP se ponen en el caso de que estas instituciones conozcan de casos individuales, y sugieren que las funciones que a ese respecto se les encomienden puedan incluir las de buscar soluciones amistosas, informar a los reclamantes de sus derechos, así como de posibles remedios legales, y transmitir a las autoridades competentes las denuncias que conozcan junto con formularles recomendaciones.

Respecto de los PP cuyos contenidos se han resumido en los párrafos precedentes, cabe observar lo siguiente:

(a) Estos principios no constituyen un instrumento vinculante de Derecho Internacional, en la medida que son recomendaciones de un órgano intergubernamental y no el texto de un tratado. Sin embargo, cada vez con mayor frecuencia los documentos de este tipo, que son adoptados por resoluciones de organismos internacionales, adquieren un peso especial como derecho internacional en formación o bien como guías y criterios que son tomados en consideración por

Pena de Muerte, 2008; Convención de las Naciones Unidas sobre los Derechos de las Personas con Discapacidad y su Protocolo Facultativo, 2008; Convenio № 169 de la OIT sobre Pueblos Indígenas y Tribales en Países Independientes, 2008; Segundo Protocolo Facultativo del Pacto Internacional de Derechos Civiles y Políticos Destinado a Abolir la Pena de Muerte, 2009; Protocolo Facultativo de la Convención Contra la Tortura y Otros Tratos o Penas Crueles, Inhumanos o Degradantes, 2009; Convención Interamericana sobre Desaparición Forzada de Personas de la Organización de los Estados Americanos, 2010.

14 Ley N²0.285 de Transparencia de la Función Pública y de Acceso a la Información de Administración del Estado, de 20 de agosto de 2008. El artículo 31 establece la autonomía del Consejo para la Transparencia.

15 Ver el texto completo en español en el sitio web http://www.nhri.net/pdf/ParisPrinciples.spanish.pdf, consultado el 5 de abril de 2010. 
diversos Estados. Ello obedece a la relevancia intrínseca de las recomendaciones, a la autoridad de la cual emanan, o bien, lo que no es menor, a los requerimientos que en ese sentido formulan organizaciones no gubernamentales de derechos humanos (las cuales ejercen, en muchos países, considerable influencia en el debate público sobre estas materias).

(b) Sin perjuicio de lo anterior, las recomendaciones del tipo de los PP suelen ser de carácter general y ampliamente inclusivas; es decir, su contenido es, por lo común, un agregado de todos los puntos que se estiman deseables a propósito de la materia sobre la que versan. En el caso de los PP ello es evidente; en efecto, las recomendaciones que contienen abarcan materias que han sido asignadas, en distintos países, a oficinas de Ombudsman o Defensor del Pueblo, procuradurías, órganos jurisdiccionales, servicios estatales de asesoría parlamentaria, departamentos de ministerios de Relaciones Exteriores y entidades educacionales, entre otras instituciones.

Tal circunstancia no ofrecería problemas insolubles si los Estados tomaran dichas recomendaciones generales como un compendio de criterios, funciones y métodos que les sirva de referencia, a la hora de crear sus propias instituciones nacionales de derechos humanos. Sin embargo, si en el proceso de establecer tales instituciones las autoridades estatales tienen en cuenta los PP como una especie de check list a la cual deben sujetarse cabalmente, existe el riesgo de que la entidad que se forme no sea debidamente funcional, en la medida en que se superpongan sus funciones con la de otros órganos del Estado o no guarde suficiente coherencia con el resto de la institucionalidad pública del país respectivo.

\section{El Instituto creado por la Ley $\mathbf{N}^{\circ} \mathbf{2 0 . 4 0 5}$ de 2010}

El texto de la Ley $N^{\circ} 20.405$ se ciñe, en buena medida a los PP en lo que se refiere a las atribuciones del Instituto. Sin embargo, agrega otras y contiene, además, un conjunto de disposiciones transitorias sobre diversas materias de derechos humanos.

En lo que sigue, se consignan las principales observaciones que suscita esta ley, a la luz de los PP y de la evolución de la institucionalidad de promoción y protección de los derechos humanos en Chile:

(a) El Instituto fue creado legalmente como una Corporación Autónoma de Derecho Público, con patrimonio propio (Art. 1). Su dirección superior corresponde a un Consejo integrado por once personas (Art. 6). La ley determina que quienes presten servicios en el Instituto se regirán por el Código del Trabajo, sin perjuicio de las normas más precisas que en materia laboral dicte el Consejo; además el Instituto y su personal quedan sujetos a las normas sobre probidad y sobre Administración Financiera del Estado, así como a la Fiscalización correspondiente por parte de la Contraloría General de la República (Arts. 12 y 8.9). La ley entrega muchas otras materias a un Estatuto que el Consejo debe proponer al Presidente de la República. Se advierte, en vista de las disposiciones mencionadas, que el legislador no se esforzó por imaginar nuevas formas de funcionamiento de un órgano autónomo, más allá de intentar no recargar la planta de la administración pública (dejando las relaciones laborales a las normas del Código del Trabajo) y de confiar los aspectos no resueltos al Estatuto que debería dictarse. En suma, se optó por una solución cansina.

(b) Entre las principales funciones del Instituto que no han sido inspiradas por los PP, se cuentan:

b.1.) Deducir acciones legales respecto de hechos que revistan carácter de genocidio, crimen contra la humanidad, crímenes de guerra y otros ilícitos contra el derecho internacional mencionados en el Art. 3.5.; también deducir recursos de amparo y de protección en el ámbito de 
su competencia. Esta norma procura satisfacer, en parte, las demandas de las organizaciones de familiares de víctimas que exigían se diera al Instituto la facultad de actuar ante la justicia respecto de causas del pasado, facultad que está radicada en el Programa de Derechos Humanos del Ministerio del Interior ${ }^{16}$. Las organizaciones de familiares, insistiendo en sus demandas, se han declarado insatisfechas con esta norma.

b.2.) Custodiar los antecedentes reunidos por las tres comisiones de verdad establecidas en Chile desde 1990, que se ocuparon de desapariciones forzosas y asesinados políticos y de prisión política y tortura, a más de los antecedentes que acopie una comisión que se crea en el artículo 3 transitorio de la Ley $N^{\circ} 20.405$.

Como puede notarse, el Instituto que establece la Ley $N^{\circ} 20.405$ tiene un mandato muy amplio que incluye funciones de investigación y elaboración de informes; recomendaciones y asesorías a las autoridades estatales; cooperación con organismos internacionales; preservación de archivos de la memoria; iniciación de acciones judiciales; educación.

La vastedad de este mandato podría corresponder, en un apropiado diseño institucional, a más de un órgano estatal.

La Ley $N^{\circ} 20.405$ se generó en un clima político preelectoral, luego de considerables demoras en su tramitación. Dado que versa sobre un tema de alta relevancia política y social, existió una premura, comprensible pero inconducente a una eficaz legislación, por aprobar la creación del Instituto, mediante acuerdos políticos y a través del arbitrio de dejar muchos aspectos entregados a un futuro Estatuto.

El establecimiento efectivo del Instituto y su debido funcionamiento deberán enfrentar las dificultades mencionadas más arriba ${ }^{17} y$, además, las que se desprenden de su diseño. En una futura edición de este Anuario esperamos poder evaluar en qué medida ha podido constituir un avance en la institucionalidad chilena de promoción y protección de los derechos humanos.

16 Ver nota 10.

17 Ver nota 4. 